\title{
TLR2 Involved in Naive CD4+ T Cells Rescues Stress-Induced Immune Suppression by Regulating Th1/Th2 and Th17
}

\author{
Jing Zhao a,d Jing Liu ${ }^{a}$ James Denney ${ }^{d}$ Chen $\mathrm{Li}^{\mathrm{c}} \quad$ Fang Li $^{\mathrm{a}}$ Fen Chang ${ }^{\mathrm{a}}$ \\ Mingyou Chen ${ }^{b}$ Deling Yin ${ }^{d}$ \\ anstitute of Developmental Biology, School of Life Science, Shandong University, and ${ }^{b}$ Department of Cardiology, \\ Qianfoshan Hospital of Shandong Province, Jinan, and ' $Q$ Qingdao Branch of Qilu Hospital, Shandong University, Qingdao, \\ China; ${ }^{d}$ Department of Internal Medicine, College of Medicine, East Tennessee State University, Johnson City, Tenn., USA
}

\section{Key Words}

Toll-like receptor 2 - Chronic stress - Naive CD4+ T cells . Mitogen-activated protein kinase $\cdot$ Immune suppression

\begin{abstract}
Stress, either physical or psychological, can have a dramatic impact on our immune system. There has been little progress, however, in understanding chronic stress-induced immunosuppression. Naive CD4+ T cells could modulate immune responses via differentiation to T helper (Th) cells. In this study, we showed that stress promotes the release of the Th1 cytokines interferon (IFN)- $\gamma$ and tumor necrosis factor (TNF)- $a$, the Th2 cytokines interleukin (IL)- 4 and IL-10 and the Th17 cytokine IL-17 of splenic naive CD4+ T cells. This suggests that stress promotes the differentiation of naive CD4+ T cells to Th1, Th2 and Th17 cells. Knockout strategies verified that TLR2 might modulate the differentiation of Th1/Th2 cells by inhibiting p38 mitogen-activated protein kinase (MAPK). Taken together, our data suggest that chronic stress induces immune suppression by targeting TLR2 and p38 MAPK in naive CD4+ T cells.

(c) 2015 S. Karger AG, Basel
\end{abstract}

(c) 2015 S. Karger AG, Basel

$1021-7401 / 15 / 0225-0328 \$ 39.50 / 0$

\section{Introduction}

Chronic restraint stress, such as long-term emotional stress, can decrease the immune response and increase susceptibility to diseases including autoimmune diseases, infectious diseases and cancer [1-3]. Various experimental systems have been explored to investigate how stress changes immune responsiveness. We and other study groups have reported that physical restraint stress modulates the immune system through the cell death receptor Fas-mediated spleen apoptotic mechanism $[2,4-6]$. Furthermore, physical restraint stress decreases the ratio of $\mathrm{T}$ helper (Th) $1 /$ Th2 cells accompanied by a decrease in spleen cells $[7,8]$. Th1 and Th2 cells are considered to be mediators of cellular immunity. The decrease of their ratio reveals mechanisms of stress-induced immune suppression. However, which kind of spleen cells are diminished and cause the imbalance of Th1/Th2 is still undefined.

Deling Yin, MD, PhD

Department of Internal Medicine, College of Medicine

East Tennessee State University, Johnson City

TN 37604 (USA)

E-Mail yin@etsu.edu

Mingyou Chen, $\mathrm{MD}, \mathrm{PhD}$

Department of Cardiology

Qianfoshan Hospital of Shandong Province, Jinan 250014 (China)

E-Mail chenmingyou123456@163.com 
Naive CD4+ T cells, an important element in spleen cells, may participate in innate immunity or amplify adaptive immune responses by differentiation to Th1, Th2 and Th17 cells, characterized by different cytokine production and functions that determine the changes in the Th1/Th2 cells $[9,10]$. So far, the numbers and differentiation of naive $\mathrm{CD} 4+\mathrm{T}$ cells in physical restraint stress are not clear.

Toll-like receptor (TLR)2, which plays a critical role both in the innate and adaptive immune responses [11, 12], is involved in regulating the differentiation of Th17 cells from naive CD4+ T cells [13]. We recently observed that an agonist of TLR2, peptidoglycan (PGN), can rescue the stress-induced decrease in interleukin (IL)-2 and the increase in IL-4 and IL-17 in stimulated CD4+ T cells and spleen cells $[14,15]$. Naive and memory CD4+ T cells are different in their immune response following stimulation, however [16]. Whether TLR2 participates in naive CD4+ T cell differentiation to Th1, Th2 and Th17 cells is not clear.

p38 Mitogen-activated protein kinase (MAPK) has emerged as a critical pathway to program dendritic cell (DC)-dependent Th17 cell differentiation by integrating multiple instructive signals in DCs [17]. As a downstream target of the TLR2 signaling pathway, p38 MAPK exerts effective immune responses, such as an increased antibacterial defense against bacterial infection as well as preventing the suppression of T-cell interferon (IFN)- $\gamma$ production following alcohol and burn injury [18-20]. Whether p38 MAPK could be modulated by TLR 2 in the differentiation of naive CD4+ T cells is still not clear.

In this study, we found that the number of naive CD4+ $\mathrm{T}$ cells decreased in stress-stimulated mice, but that the Th1/Th2 ratio and Th17 production were upregulated. This might be explained by a compensatory function of naive $\mathrm{CD} 4+\mathrm{T}$ cells in restraint-induced immune suppression. TLR2 and p38 MAPK may be involved in this process by the regulation of the Th1/Th2 ratio and Th17 production.

\section{Materials and Methods}

\section{Mice}

TLR2 knockout (KO) mice, on a C57BL/6 background and wild-type C57BL/6 mice were obtained from the Jackson Laboratory (Bar Harbor, Me., USA), and maintained in the Division Laboratory of Animal Resources at the East Tennessee State University, a facility accredited by the Association for the Assessment and Accreditation of Laboratory Animal Care International. All aspects of the animal care and experimental protocols were approved by the University's Committee on Animal Care.

\section{Physical Restraint}

Six- to eight-week-old male mice were subjected to an established chronic physical restraint protocol used in our laboratory and others $[7,21]$. Briefly, the mice were placed in a $50-\mathrm{ml}$ conical centrifuge tube with multiple punctures to allow ventilation. They were held horizontally in the tubes for $12 \mathrm{~h}$. Control littermates were kept in their original cage without food and water for $12 \mathrm{~h}$. After the physical restraint, the mice were sacrificed by $\mathrm{CO}_{2}$ asphyxiation, and the spleens and serum were harvested.

\section{Experimental Protocols}

One hour before the initiation of the physical restraint, the animals received a single intraperitoneal (i.p.) injection of PGN (50 $\mu \mathrm{g} / 25 \mathrm{~g}$ body weight; Sigma, St Louis, Mo., USA) or p38 MAPK inhibitor SB203580 (30 $\mu \mathrm{g} / 25 \mathrm{~g}$ body weight; Tocris Bioscience, Bristol, UK) in $400 \mu \mathrm{l}$ of sterile saline or $1 \mu \mathrm{l}$ of solvent control (DMSO) and in $400 \mu \mathrm{l}$ sterile saline for the controls. After the physical restraint, the mice were sacrificed by $\mathrm{CO}_{2}$ asphyxiation, and the spleens were harvested.

\section{Culture and Stimulation of CD4+ T Cells}

Splenic naive CD4+ T cells were negatively selected by using the MagCellect ${ }^{\mathrm{TM}}$ cell selection kits and reagents (R\&D Systems, Minneapolis, Minn., USA). Isolated CD4+ T cells were plated in 96-well culture plates at $2.5 \times 10^{5}$ per well. The culture medium used was Gibco ${ }^{\circledR}$ RPMI Media 1640 (Invitrogen, Carlsbad, Calif., USA) supplemented with $10 \%$ heat-inactivated fetal calf serum, $2 \mathrm{mM}$ L-glutamine, $100 \mathrm{U} / \mathrm{ml}$ penicillin, $100 \mathrm{mg} / \mathrm{ml}$ streptomycin, $5 \mu \mathrm{g} / \mathrm{ml}$ anti-CD3 and $1 \mu \mathrm{g} / \mathrm{ml}$ anti-CD28 (BD Pharmingen). AntiCD3 and anti-CD28 are used to mimic antigen stimulation [22].

\section{Enzyme-Linked Immunosorbent Assay}

The supernatants from anti-CD3/anti-CD28-stimulated CD4+ T cells cultures were collected after 24 and $48 \mathrm{~h}$. The secretion of several Th 1 cytokines including IFN- $\gamma$ and tumor necrosis factor(TNF)- $\alpha$ and of the Th 2 cytokines IL- 4 and IL-10 were examined by using a Quantikine Mouse ELISA kit (R\&D Systems). The Th17 cytokine IL-17 was quantified using a mouse IL-17 platinum ELISA kit (eBioscience, Vienna, Austria).

\section{Real-Time Quantitative Reverse Transcription Polymerase}

\section{Chain Reaction}

Total RNA was isolated from splenic naive CD4+ T cells using an RNeasy Plus mini kit (QIAGEN Sciences, Germantown, Md., USA). Real-time PCR was performed as described previously [5, 14]. Briefly, $1 \mathrm{mg}$ of RNA from each sample was used for the reverse transcription and synthesis of cDNA using a Reaction Rea$\mathrm{dy}^{\mathrm{TM}}$ first-strand cDNA synthesis kit (SABiosciences, Frederick, Md., USA). PCR was performed using RT ${ }^{2}$ SYBR Green fluorescein PCR master mix (SABiosciences). GAPDH expression was used as an internal control. The primer sequences used were as follows: IL-4 forward 5'-GGT CTC AAC CCC CAG CTA GT-3', IL-4 reverse $5^{\prime}$-TAG TGA ACT CTC TCT AGT AGC CG-3', IL-10 forward $5^{\prime}$-GCT CTT ACT GAC TGG CAT GAG-3', IL-10 reverse $5^{\prime}$-CGC AGC TCT AGG AGC ATG TG-3', TNF-a forward $5^{\prime}$ GCA CCA CCA TCA AGG ACT CAA-3',TNF- $\alpha$ reverse $5^{\prime}$-TTG CAG AAC TCA GGA ATG GAC A, IFN- $\gamma$ forward $5^{\prime}$-TGC TGA TGG GAG GAG ATG TCT AC- $3^{\prime}$, IFN- $\gamma$ reverse $5^{\prime}$-ACC TGA CAC ATT CGA GTG CTG T-3', IL-17 forward $5^{\prime}$-GCC CTC AGA CTA CCT CAA CC-3', IL-17 reverse 5'-GAA TTC ATG TGG 


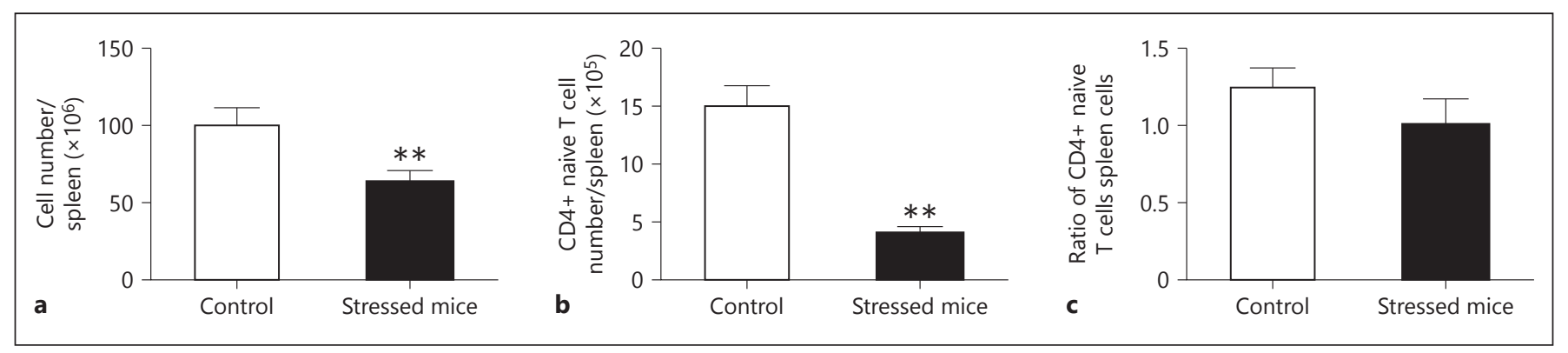

Fig. 1. Stress decreased the number of splenic naive CD4+ T cells. Wild-type C57BL/6 mice aged 6-8 weeks were subjected to a 12hour physical restraint daily for 2 days, and then sacrificed by $\mathrm{CO}_{2}$ asphyxiation. After separation, spleen cells (a) and total splenic

TGG TCC AG-3', GAPDH forward 5' -TGA CCA CAG TCC ATG CCA TC- $3^{\prime}$ and GAPDH reverse $5^{\prime}$-GAT GGG GGT TAC ACA GGC AG-3'.

\section{Western Blot Analysis}

Cytoplasmic proteins were prepared from splenic tissue and immunoblot analysis was performed as described [6]. Briefly, total proteins were extracted with the use of RIPA lysis buffer (Pierce Biotechnology, Rockford, Ill., USA). Samples containing equal amounts of protein were separated by $10 \%$ SDS-PAGE and transferred onto Hybond ${ }^{\mathrm{TM}}$ ECL membranes (Amersham Pharmacia Biotech, Piscataway, N.J., USA), which were incubated overnight at $4^{\circ} \mathrm{C}$ with the appropriate primary antibodies (anti-phospho-p38 MAPK, anti-p38 MAPK, anti-phosphor-p65 NF- $\kappa$ B, anti-p65 NF$\kappa B$, anti-phosphor-JNK, anti-JNK (Cell Signaling Technology, Beverly, Mass., USA; 1:1,000), and then incubated for $1 \mathrm{~h}$ at room temperature with peroxidase-conjugated secondary antibodies (Cell Signaling Technology; 1:5,000). Blots were exposed to the SuperSignal West Dura Extended Duration Substrate (Pierce Biotechnology). Signals were quantified by scanning densitometry with the Bioimage analysis system (Bio-Rad).

\section{Statistical Analysis}

The results were presented as means \pm SD. The data were analyzed using one-way analysis of variance and the Student $t$ test. $\mathrm{p}<$ 0.05 was considered to be statistically significant.

\section{Results}

\section{Stress Decreased the Number of Splenic Naive CD4+ T Cells}

Naive CD4+ T cells purified from restraint stress mice and control mice were counted after Trypan blue staining. The ratio of naive $\mathrm{CD} 4+\mathrm{T}$ cells/spleen cells was then calculated. The results showed that restraint stress decreases the count of naive CD4+ T cells as well as spleen cells (fig. 1a, b), but no changes in this ratio were observed in the spleen (fig. 1c). naive CD4+ T cells (b) were enumerated by means of Trypan blue staining. $\mathbf{c}$ The ratio of splenic naive CD4+ T cells/spleen cells was then calculated. Means and SDs were calculated from 7 mice in each group. ${ }^{* *} \mathrm{p}<0.01$ vs. nonstressed control.

\section{Stress Modulated Th1, Th2 and Th17 Cell}

Differentiation and Upregulated the Th1/Th2 Ratio in

Naive CD4+ T Cells

Naive T cells can only be activated by antigen that is presented by DCs. CD3 and CD28 antibodies were used to mimic the antigen presentation process [23]. After 24 and $48 \mathrm{~h}$ of stimulation, the differentiation of Th1, Th2 and Th17 cells was evaluated according to the production of cytokines. The expression and secretion of several Th1 cytokines, including IFN- $\gamma$ and TNF- $\alpha$, of the Th2 cytokines IL- 4 and IL- 10 and the Th17 cytokine IL-17 were all significantly increased after stress (fig. 2a-c); this suggests that stress could enhance the differentiation of Th1, Th2 and Th17 cells from naive CD4+ T cells. Four ratios could be obtained from these cytokines to reflect the ratio of Th1/Th2; all four showed increased ratios of Th1/Th2. Here, the ratio of $\mathrm{Th} 1 / \mathrm{Th} 2$, calculated according to the production of TNF- $\alpha$ to IL-10, was supported as a representative result (fig. $2 \mathrm{~d}$ ). These results indicated that naive $\mathrm{CD} 4+\mathrm{T}$ cells had potential immune system regulatory effects.

TLR2 Is Involved in the Differentiation of Naive CD4+ T Cells to Th17 Cells

TLRs play a critical role in regulating the inflammatory response and innate immunity $[14,19]$. We next determined the effects of restraint stress on the production of Th17 cytokines in TLR2 KO mice and wild-type mice. Two days after restraint stress, culture supernatants from CD3/CD28 antibody-stimulated naive CD4+ T cells were analyzed for levels of the Th17 cytokine IL-17 by ELISA. We found that the naive cells from the stressed TLR2 KO mice produced a dramatically greater amount of IL-17 than those from the stressed wild-type mice (fig. 3a). 
Fig. 2. Stress promoted Th1, Th2 and Th17 cell differentiation and upregulated the Th1/Th2 ratio in naive CD4+ T cells. After the mice had been stressed for 2 days, splenic naive CD4+ T cells were separated (method as in fig. 1), and then stimulated with anti-CD3 and anti-CD28 monoclonal antibodies for 24 and $48 \mathrm{~h}$ to mimic the antigen presentation process. The differentiation of Th1, Th2 and Th17 cells was evaluated according to the production of cytokines. The expression and secretion of several Th1 cytokines including IFN $-\gamma$ and TNF- $\alpha$ (a), of the Th2 cytokines IL- 4 and IL-10 (b) and of the Th17 cytokine IL-17 (c) were analyzed by RT-PCR and ELISA, respectively. The ratio of Th1/Th2 was calculated (d). ${ }^{* *} \mathrm{p}<0.01$ versus nonstressed control.

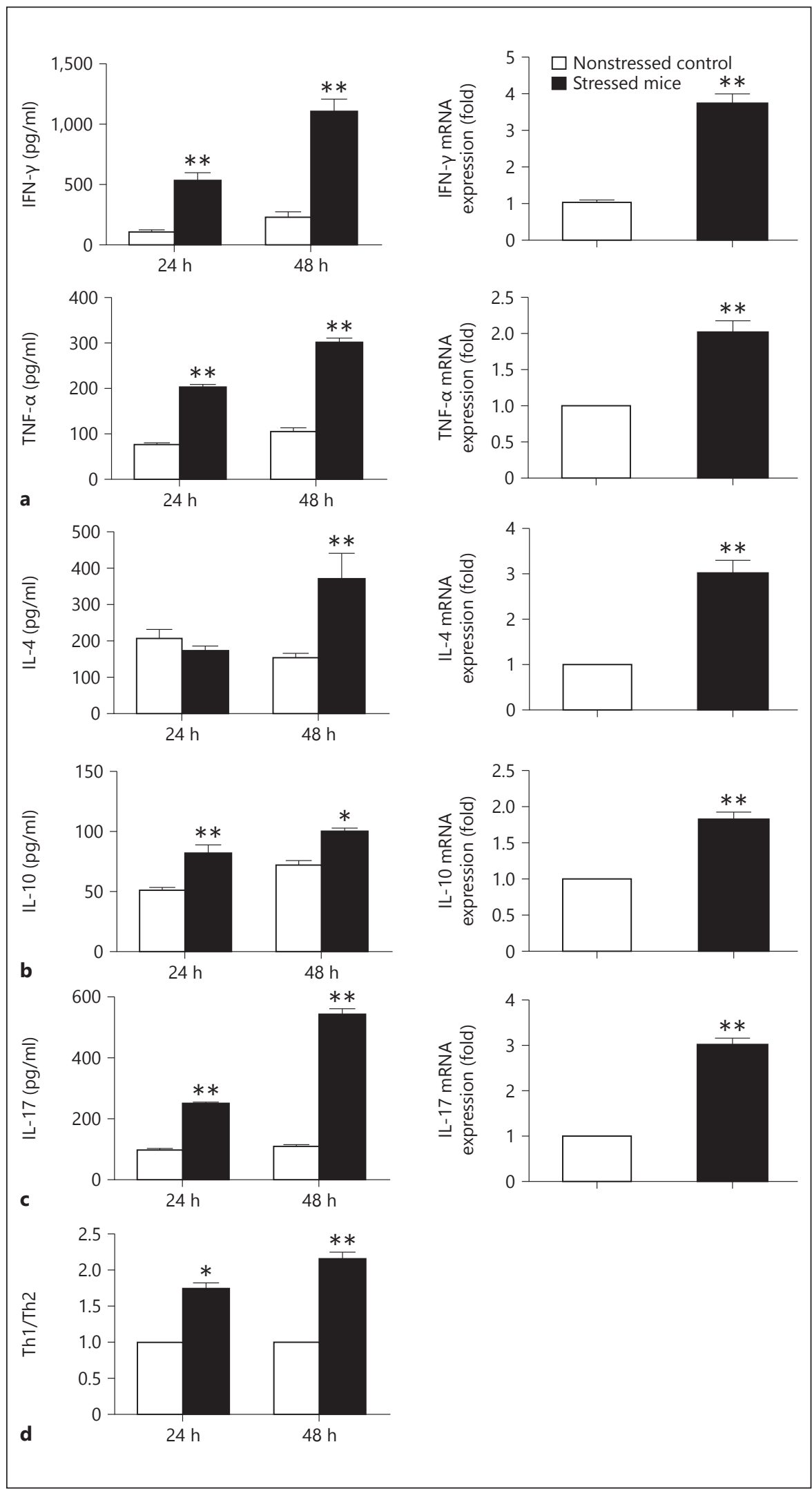




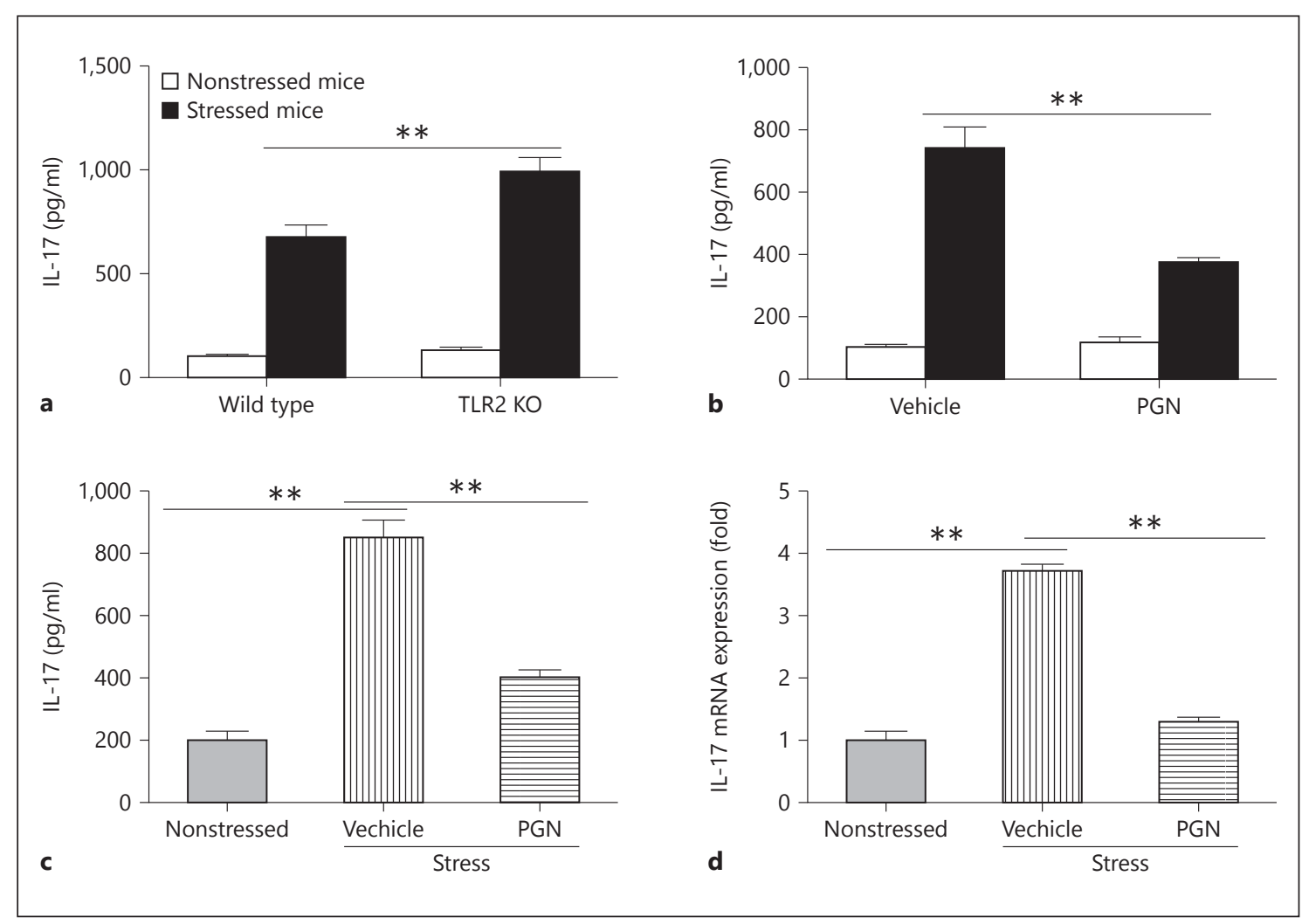

Fig. 3. TLR2 hampered the differentiation of naive CD4+ T cells to Th1, Th2 and Th17 cells. a We determined the effects of restraint stress on the Th17 cytokine production in TLR2 KO mice and wild-type mice. Two days after the restraint stress of the mice, culture supernatants from CD3/CD28 antibody-stimulated naive CD4+ T cells were analyzed for the level of the Th17 cytokine IL17 by ELISA. b Wild-type (C57BL/6) mice were administered PGN (50 $\mu \mathrm{g} / 25 \mathrm{~g}$ body weight, i.p.) or no PGN $1 \mathrm{~h}$ before being subjected to restraint stress $(n=6 /$ group). Two days after the re-

To verify the role of TLR2 in stress-stimulated Th17 differentiation from naive $\mathrm{CD} 4+\mathrm{T}$ cells, wild-type (C57BL/6) mice were administered PGN or no PGN $1 \mathrm{~h}$ before being subjected to restraint stress. PGN is a TLR2 ligand which activates cellular signaling specifically via TLR2 [24, 25]. Our previous report showed that administration of PGN in stressed mice decreased the expression of TLR2 compared to stressed control mice [15]. After 2 days of stress, the IL-17 production by naive CD4+ $\mathrm{T}$ cells was detected as described above. The results showed that naive CD4+ T cells from stressed mice treated with PGN produced dramatically less IL-17 than these cells in stressed wild-type mice that did not receive PGN (fig. 3b).

To exclude the complex effect of environment in vivo, we separated the naive $\mathrm{CD} 4+\mathrm{T}$ cells from the stressed and straint stress of the mice, culture supernatants from $\mathrm{CD} 3 / \mathrm{CD} 28$ antibody-stimulated naive $\mathrm{CD} 4+\mathrm{T}$ cells were analyzed for the level of IL-17 by ELISA. c After 2 days of stress, we separated naive CD4+ T cells from stressed and nonstressed mice, and then treated the cells with PGN in vitro. The culture supernatants from the $\mathrm{CD} 3 / \mathrm{CD} 28$ antibody-stimulated naive CD4+ T cells were analyzed for the production of IL-17 by ELISA. $\mathbf{d}$ RNA extracted from the $\mathrm{CD} 3 / \mathrm{CD} 28$ antibody-stimulated naive $\mathrm{CD} 4+\mathrm{T}$ cells was used for RT-PCR to detect the expression of IL-17. ${ }^{* *} \mathrm{p}<0.01$. nonstressed mice first, and then treated the cells with PGN in vitro. PGN also inhibited IL-17 production and expression in vitro (fig. $3 \mathrm{c}, \mathrm{d}$ ). Taken together, our results suggest that TLR2 inhibited Th17 differentiation. Our data support the conspicuous role of TLR2 in the stressstimulated naive $\mathrm{CD} 4+\mathrm{T}$ cell immune response.

\section{p38 MAPK Is Involved in the Differentiation of Naive CD4+ T Cells to Th17 Cells}

p38 MAPK is a well-known downstream target of TLRs in the immune response $[19,26]$. To clarify the mechanisms of TLR2-mediated naive CD4+ T cell differentiation, we detected changes in these cells in spleen tissue by Western blot. We showed that chronic stress activated p38 MAPK but decreased the level of JNK and p65 phosphorylation (fig. 4a). 
Fig. 4. p38 MAPK promoted the differentiation of naive CD4+ T cells to Th1, Th2 and Th17 cells. a Mice aged 6-8 weeks were subjected to 6 and $12 \mathrm{~h}$ of physical restraint stress. After that, spleens were collected for the determination of phosphorylation ( $\mathrm{p}-$ ) of p38 MAPK, p65 and JNK by Western blot. b C57BL/6 mice were administered SB203580 (30 $\mu \mathrm{g} / 25 \mathrm{~g}$ body weight, i.p.) or no SB203580 $1 \mathrm{~h}$ before being subjected to restraint stress ( $n=6 /$ group). Two days after the restraint stress of the mice, culture supernatants from CD3/CD28 antibodystimulated naive CD4+ T cells were analyzed for the level of IL-17 by ELISA. ${ }^{* *} \mathrm{p}<$ 0.01 .

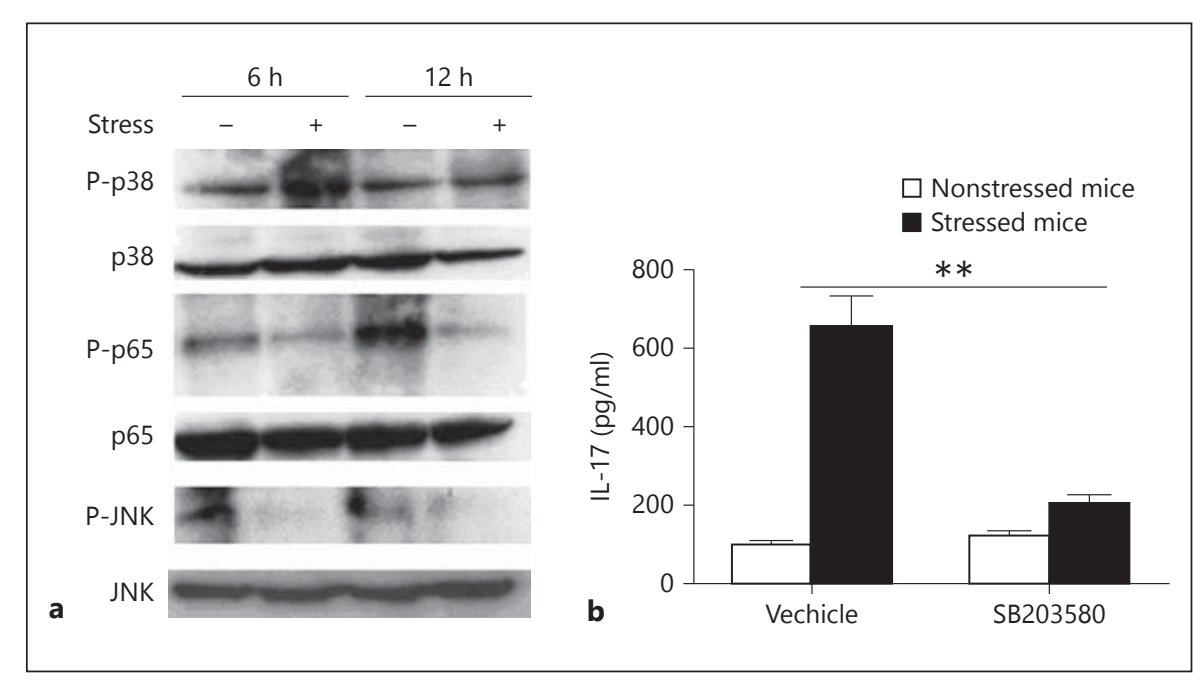

To determine whether p38 MAPK is involved in the differentiation of naive CD4+ T cells to Th17 cells, wildtype mice were administered with the $\mathrm{p} 38$ MAPK inhibitor SB203580 [27]. After 2 days of stress, the IL-17 production by naive CD4+ T cells was detected by ELISA. The results showed that naive CD4+ T cells from stressed mice treated with SB203580 produced dramatically less IL-17 than those from stressed wild-type mice that did not receive SB203580 (fig. 4b).

\section{TLR2 and p38 MAPK Both Contributed to the}

Stress-Stimulated Differentiation of Th1 and Th2 Cells

To explore the roles played by TLR 2 and p38 MAPK in stress-stimulated Th1 and Th2 cell differentiation, the secretion of Th1 cytokines including IFN- $\gamma$ and TNF- $\alpha$ and the Th2 cytokine IL- 4 were all detected by ELISA after PGN or SB203580 administration and stress. The results showed that PGN and SB203580 can both inhibit the stress-stimulated release of IFN- $\gamma$, TNF- $\alpha$ and IL-4 (fig. 5). This suggests that TLR2 hampers and p38 MAPK promotes stressstimulated differentiation of Th1 and Th2 cells.

\section{The Relationship between TLR2 and p38 MAPK in Stress-Induced Differentiation of Th1, Th2 and Th17 Cells}

To verify that TLR2 modulated Th1, Th2 and Th17 cell differentiation by inhibiting p38 MAPK, wild-type mice received an i.p. injection of $\mathrm{PGN}$, and $30 \mathrm{~min}$ later, they received another i.p. injection of SB203580 or its vehicle. The secretion of IL-17, IL- 4 and IFN- $\gamma$ were then detected. The results showed that SB203580 further suppressed the PGN-decreased production of IFN- $\gamma$ and IL-4 (fig. $6 \mathrm{~b}, \mathrm{c}$ ). The superimposed effect of PGN and SB203580 indicated that TLR2 might modulate the differentiation of naive CD4+ $\mathrm{T}$ cells by suppression of $\mathrm{p} 38$ MAPK activity. SB203580 did not affect the PGN-decreased production of IL-17 (fig. 6a), however, which suggests that they might regulate the release of IL-17 via a different pathway (fig. 6d).

\section{Discussion}

In our previous studies, we have reported that stress caused apoptosis of spleen cells and CD4+ T cells $[14,15]$. Within the blood and lymphoid organs, the majority of $\mathrm{T}$ cells are antigen-naive T cells, with only a small proportion being memory $\mathrm{T}$ cells. Furthermore, naive and memory $\mathrm{CD} 4+\mathrm{T}$ cells are different in their susceptibilities to human antigen infection stimulation [28]. However, the effect of stress on naive CD4+ T cells is not clear. In this study, we documented that the number of naive $\mathrm{CD} 4+\mathrm{T}$ cells also decreased by stress, but that the ratio to spleen cells is not changed. Furthermore, we analyzed the potential function of naive CD4+ T cells in stress-induced immune suppression by the production of cytokines. The results showed that naive CD4+ T cells can upregulate the ratio of Th1/Th2 cells and promote the differentiation of Th17. The data demonstrate that restraint stress induces an imbalance in the Th1 and Th2 responses. However, whether naive CD4+ $T$ cells can activate the immune response or increase the risk of autoimmune reactions is unclear. Canonical transcription factors need to be studied to precisely determine their role in $\mathrm{CD} 4+\mathrm{T}$ cell differentiation. Flow cytometry can reflect the differentiation directly.

Naive $T$ cells can only be activated by antigens presented by DCs. After initial antigenic activation, naive $\mathrm{T}$ 


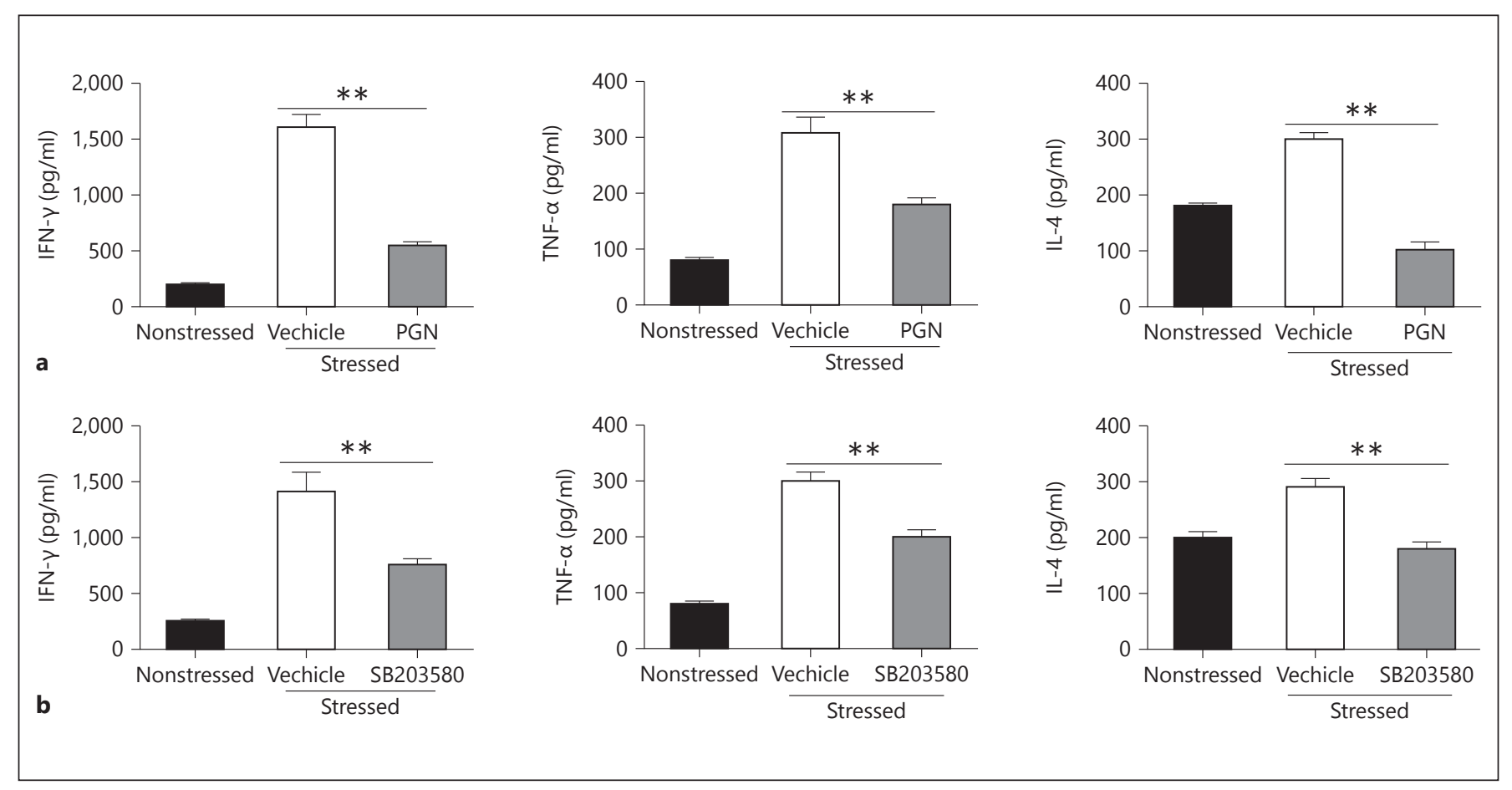

Fig. 5. TLR 2 and p 38 MAPK both control the differentiation of naive CD4+ T cells to Th1 and Th2 cells. C57BL/ 6 mice were administered with PGN, SB203580 or the corresponding vehicles (as in figs. 3, 4; $\mathrm{n}=6$ /group). Two days after the restraint stress of the mice, culture supernatants of CD3/CD28 antibody-stimulated naive CD4+ T cells from PGN (a) or SB203580 (b) treated mice were analyzed for the level of the Th1 cytokines IFN- $\gamma$ and TNF- $\alpha$ and the Th 2 cytokine IL- 4 by ELISA. ${ }^{* *} \mathrm{p}<0.01$. cells develop into an intermediate-stage cell, called the Th0 cell, which can then be activated by antigen-presenting cells, e.g. DCs. CD3 and CD28 antibodies are in popular use for mimicking T cell receptor/major histocompatibility complex interactions, in order to activate the differentiation of naive T cells [23]. Although the importance of such interactions in T-cell activation has been demonstrated, the cellular mechanisms driving naive CD4+ T cells are not fully understood. It has been reported that TLR2 regulates the Th17 cell differentiation of naive CD4+ T cells [13]. In this study, we verified the function of TLR 2 in Th17 cell differentiation from stressstimulated naive CD4+ T cells, and found that TLR2 also play a vital role in $\mathrm{Th} 1$ and $\mathrm{Th} 2$ cell differentiation from stress-stimulated naive CD4+ T cells.

We verified that $\mathrm{p} 38 \mathrm{MAPK}$ is another factor that promotes the differentiation of naive CD4+ T cells to Th1, Th2 and Th17 cells. p38 MAPK could be activated by a variety of inflammatory stimuli including cytokines and lipopolysaccharide, thus $\mathrm{p} 38 \mathrm{MAPK}$ inhibition was found to reduce cytokine release in several cell types [27, 29]. However, in mast cells, the opposite effect was observed [30]. Considering the cell-specific activity of p38 MAPK in inflammation, we analyzed its function in $\mathrm{CD} 3 / \mathrm{CD} 28$ antibody-stimulated naive $\mathrm{CD} 4+\mathrm{T}$ cell differentiation and found that it promoted the production of various interleukins. p38 MAPK thus has an important function in promoting the differentiation of naive CD4+ T cells.

The superimposed effect of PGN and SB203580 on the release of Th1, Th2 cytokines indicated that TLR2 might modulate the differentiation of naive CD4+ T cells to Th1 and Th2 cells by the suppression of p38 MAPK activity. SB203580 did not affect the PGN-decreased production of IL-17 (fig. 6), so they might regulate release of IL-17 via different pathways. Further research on the roles of TLR 2 and p 38 MAPK in Th17 cell differentiation is required.

The current stress protocol, which uses repeated homotypic stress to induce anxious and depressive phenotypes, is proposed as a model for the study of some aspects of depressive-like symptoms in mice which are similar to those occurring in humans. This protocol involves both physical and psychological changes which are reflected differently physiologically, depending on whether they are caused by repeated homotypic or heterotypic stress [31]. Previous reports support a role for endocannabi- 


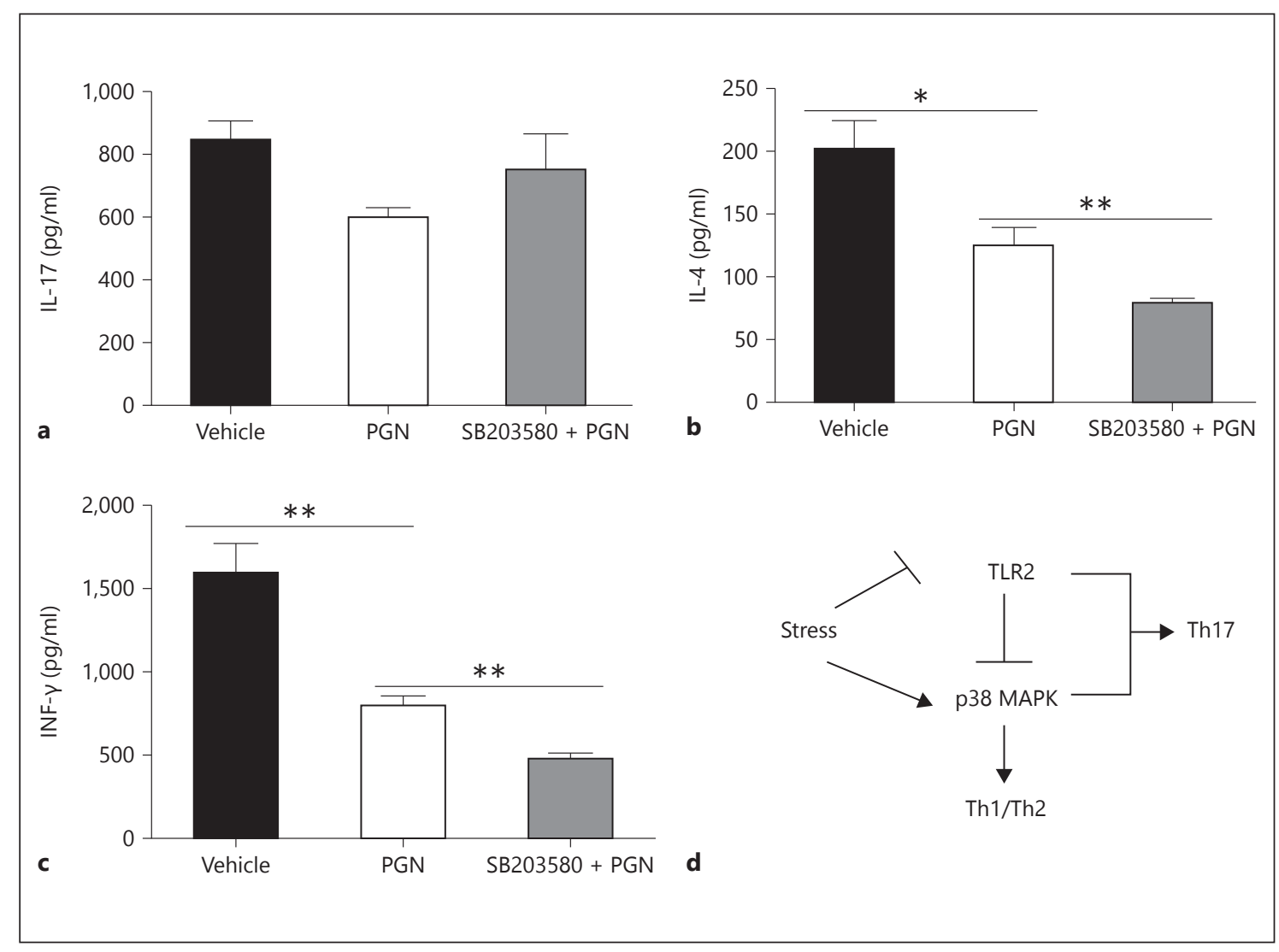

Fig. 6. The relationship between TLR2 and p38 MAPK in stressinduced Th1, Th2 and Th17 cell differentiation. One hour before the initiation of stress, wild-type mice received an i.p. injection of PGN and 30 min later, they received an i.p. injection of SB203580 or its vehicle. Two days after the restraint stress of the mice, culture

noid signaling in the response of the central nervous system to chronic, homotypic stress and, specifically, in the process of stress-response habituation [31]. It has been reported that chronic exposure to stressors decreases thyroid hormone levels and reduces $\mathrm{T}$ lymphocyte proliferation in response to concanavalin A [32]. However; whether the hormones also participate in naive CD4+ $\mathrm{T}$ cells rescuing stress-induced immune suppression still needs further study. Moreover, because the receptors across different tissues vary, e.g. in the blood versus the spleen, it follows that differences in stress-related effects can be expected. In addition, although chronic stressors are deleterious to immune function, very brief stressors can enhance some of the aspects of immune function, such as the trafficking of cells from the lymphoid organs to the peripheral blood and the skin. Therefore, the effects of acute versus chronic stress on splenic cellular composition may differ.

TLR2-Mediated Immune Suppression supernatants from CD3/CD28 antibody-stimulated naive CD4+ T cells were analyzed for the secretion of IL-17 (a), IL-4 (b) and IFN- $\gamma(\mathbf{c})$ by ELISA. $\mathbf{d}$ Schematic of the signaling pathways of stress in the naive CD4+ T cells.

In summary, we found that the number of naive CD4+ $\mathrm{T}$ cells decreased in stressed mice, but that the Th1/Th2 ratio and Th17 production were upregulated. TLR 2 and p38 MAPK might be involved in this process by regulating the Th1/Th2 ratio and Th17 differentiation. Our data suggest a new clue for curing stress-induced immune suppression by targeting TLR2 and p38 MAPK in naive CD4+ T cells.

\section{Acknowledgments}

This work was supported in part by the NIH grant No. NIGM094740.

\section{Disclosure Statement}

The authors declare that there are no conflicts of interest.

Neuroimmunomodulation 2015;22:328-336 DOI: $10.1159 / 000371468$ 


\section{References}

1 Dhabhar FS, McEwen BS: Acute stress enhances while chronic stress suppresses cellmediated immunity in vivo: a potential role for leukocyte trafficking. Brain Behav Immun 1997;11:286-306.

-2 Shi Y, Devadas S, Greeneltch KM, Yin D, Allan Mufson R, Zhou JN: . Stressed to death: implication of lymphocyte apoptosis for psychoneuroimmunology. Brain Behav Immun 2003;17(suppl 1):S18-S26.

3 Hawkley LC, Cacioppo JT: Stress and the aging immune system. Brain Behav Immun 2004;18:114-119.

4 Li H, Zhao J, Chen M, Tan Y, Yang X, Caudle $\mathrm{Y}$, Yin D: Toll-like receptor 9 is required for chronic stress-induced immune suppression. Neuroimmunomodulation 2014;21:1-7.

$\checkmark 5$ Yin D, Tuthill D, Mufson RA, Shi Y: Chronic restraint stress promotes lymphocyte apoptosis by modulating CD95 expression. J Exp Med 2000;191:1423-1428.

6 Yin D, Zhang Y, Stuart C, Miao J, Zhang Y, Li C, Zeng X, Hanley G, Moorman J, Yao Z, Woodruff M: Chronic restraint stress modulates expression of genes in murine spleen. J Neuroimmunol 2006;177:11-17.

7 Zhang Y, Woodruff M, Zhang Y, Miao J, Hanley G, Stuart C, Zeng X, Prabhakar S, Moorman J, Zhao B, Yin D: Toll-like receptor 4 mediates chronic restraint stress-induced immune suppression. J Neuroimmunol 2008a; 194:115-122.

8 Zhang Y, Zhang Y, Miao J, Hanley G, Stuart C, Sun X, Chen T, Yin D: Chronic restraint stress promotes immune suppression through toll-like receptor 4-mediated phosphoinositide 3-kinase signaling. J Neuroimmunol 2008b;204:13-19.

-9 Sambucci M, Laudisi F, Novelli F, Bennici E, Rosado MM, Pioli C: Effects of PARP-1 deficiency on Th1 and Th2 cell differentiation. Sci World J 2013;2013:375024.

10 Suzuki D, Furukawa K, Kimura F, Shimizu H, Yoshidome H, Ohtsuka M, Kato A, Yoshitomi H, Miyazaki M: Effects of perioperative immunonutrition on cell-mediated immunity, T helper type 1 (Th1)/Th2 differentiation, and Th17 response after pancreaticoduodenectomy. Surgery 2010;148:573-581.

-11 Lin H, Yan J, Wang Z, Hua F, Yu J, Sun W, Li K, Liu H, Yang H, Lv Q, Xue J, Hu ZW: Loss of immunity-supported senescence enhances susceptibility to hepatocellular carcinogenesis and progression in Toll-like receptor 2-deficient mice. Hepatology 2013;57:171182 .
12 Oberg HH, Juricke M, Kabelitz D, Wesch D: Regulation of T cell activation by TLR ligands. Eur J Cell Biol 2011;90:582-592.

13 Nyirenda MH, Sanvito L, Darlington PJ, O’Brien K, Zhang GX, Constantinescu CS, Bar-Or A, Gran B: TLR2 stimulation drives human naive and effector regulatory $\mathrm{T}$ cells into a Th17-like phenotype with reduced suppressive function. J Immunol 2011;187:22782290.

14 Hu D, Denney J, Liang M, Javer A, Yang X, Zhu R, Yin D: Stimulatory Toll-like receptor 2 suppresses restraint stress-induced immune suppression. Cellular Immunol 2013;283:1824.

15 Li H, Chen L, Zhang Y, Lesage G, Zhang Y, Wu Y, Hanley G, Sun S, Yin D: Chronic stress promotes lymphocyte reduction through TLR2-mediated PI3K signaling in a beta-arrestin 2 dependent manner. J Neuroimmunol 2011;233:73-79.

16 Riley JL, Levine BL, Craighead N, Francomano T, Kim D, Carroll RG, June CH: Naive and memory CD4 T cells differ in their susceptibilities to human immunodeficiency virus type 1 infection following CD28 costimulation: implications for transmission and pathogenesis. J Virol 1998;72:8273-8280.

17 Huang G, Wang Y, Chi H: Regulation of TH17 cell differentiation by innate immune signals. Cell Mol Immunol 2012;9:287-295.

18 Li D, Lei H, Li Z, Li H, Wang Y, Lai Y: A novel lipopeptide from skin commensal activates TLR2/CD36-p38 MAPK signaling to increase antibacterial defense against bacterial infection. PloS One 2013;8:e58288.

19 Li X, Rendon JL, Akhtar S, Choudhry MA: Activation of toll-like receptor 2 prevents suppression of $\mathrm{T}$-cell interferon gamma production by modulating p38/extracellular signal-regulated kinase pathways following alcohol and burn injury. Mol Med 2012;18:982991.

20 Jarnicki AG, Conroy H, Brereton C, Donnelly G, Toomey D, Walsh K, Sweeney C, Leavy O, Fletcher J, Lavelle EC, Dunne P, Mills KH: Attenuating regulatory $\mathrm{T}$ cell induction by TLR agonists through inhibition of p38 MAPK signaling in dendritic cells enhances their efficacy as vaccine adjuvants and cancer immunotherapeutics. J Immunol 2008;180:37973806 .

21 Sheridan JF, Dobbs C, Jung J, Chu X, Konstantinos A, Padgett D, Glaser R: Stress-induced neuroendocrine modulation of viral pathogenesis and immunity. Ann NY Acad Sci 1998;840:803-808.

$\checkmark 22$ Roy S, Wang J, Charboneau R, Loh HH, Barke RA: Morphine induces CD4+ T cell IL-4 expression through an adenylyl cyclase mechanism independent of the protein kinase A pathway. J Immunol 2005;175:6361-6367.
23 Min B, Foucras G, Meier-Schellersheim M, Paul WE: Spontaneous proliferation, a response of naive CD4 T cells determined by the diversity of the memory cell repertoire. Proc Natl Acad Sci U S A 2004;101:3874-3879.

$24 \mathrm{Ha}$ T, Lu C, Liu L, Hua F, Hu Y, Kelley J, Singh K, Kao RL, Kalbfleisch J, Williams DL, Gao X, Li C: TLR2 ligands attenuate cardiac dysfunction in polymicrobial sepsis via a phosphoinositide 3-kinase-dependent mechanism. Am J Physiol Heart Circ Physiol 2010; 298:H984-H991.

25 Abrahams VM, Aldo PB, Murphy SP, Visintin I, Koga K, Wilson G, Romero R, Sharma S, Mor G: TLR6 modulates first trimester trophoblast responses to peptidoglycan. J Immunol 2008; 180:6035-6043

26 Zhu J, Mohan C: Toll-like receptor signaling pathways - therapeutic opportunities. Mediators Inflamm 2010;2010:781235.

27 Beyaert R, Cuenda A, Vanden Berghe W, Plaisance S, Lee JC, Haegeman G, Cohen P, Fiers $\mathrm{W}$ : The p38/RK mitogen-activated protein kinase pathway regulates interleukin- 6 synthesis response to tumor necrosis factor. EMBO J 1996;15:1914-1923.

28 Naarding MA, Ludwig IS, Groot F, Berkhout B, Geijtenbeek TB, Pollakis G, Paxton WA: Lewis $\mathrm{X}$ component in human milk binds DC-SIGN and inhibits HIV-1 transfer to CD4+ T lymphocytes. J Clin Invest 2005;115: 3256-3264.

29 Lee JC, Laydon JT, McDonnell PC, Gallagher TF, Kumar S, Green D, McNulty D, Blumenthal MJ, Heys JR, Landvatter SW, et al: A protein kinase involved in the regulation of inflammatory cytokine biosynthesis. Nature 1994;372:739-746.

30 Zhang C, Baumgartner RA, Yamada K, Beaven MA: Mitogen-activated protein (MAP) kinase regulates production of tumor necrosis factor-alpha and release of arachidonic acid in mast cells. Indications of communication between p38 and p42 MAP kinases. J Biol Chem 1997;272:13397-13402.

-31 Patel S, Hillard CJ: Adaptations in endocannabinoid signaling in response to repeated homotypic stress: a novel mechanism for stress habituation. Eur J Neurosci 2008;27: 2821-2829.

32 Frick LR, Rapanelli M, Bussmann UA, Klecha AJ, Arcos ML, Genaro AM, Cremaschi GA: Involvement of thyroid hormones in the alterations of T-cell immunity and tumor progression induced by chronic stress. Biol Psychiatry 2009;65:935-942. 